\title{
The Effect of Ultrasonic Treatment on Dyeing of Luffa Cylindrica Fibres
}

\author{
Burcu YILMAZ ŞAHINBAŞKAN \\ Marmara University, Faculty of Technology, Department of Textile Engineering, Istanbul, Turkey
}

\begin{abstract}
In this research work, conventional and ultrasonic treatments on exhaust dyeing of natural Luffa cylindrical (LC) fibres with reactive dyes were studied. Accordingly, the samples were alkali scoured, bleached with H2O2 and dyed with C.I. Reactive Red 241 and C.I. Reactive Blue 19 at $60 \mathrm{C}, 60 \mathrm{~min}$ with or without ultrasonic energy. The colouristic properties, penetration behaviour and colour fastnesses were investigated and compared with each other. Using ultrasonic energy for dyeing LC fibres enhances the exhaustion of dye, good colouristic properties and colour fastnesses in dyeings are achieved. The ultrasonic power seems promising since it enhances colour yields and reduces process time.
\end{abstract}

Keywords: luffa cylindrica fibres, ultrasonic energy, dyeing of luffa cylindrica fibres.

\section{INTRODUCTION}

Luffa cylindrica (LC) is available in the wet and warm climates of the world, commonly grown in Japan, China and other Asian countries and also quite common in Central and South America. In Turkey LC fibre grows as well in the areas of Mediterranean climate. The fibre is a subtropical plant of the cucurbit family, which produces a fruit with a fibrous vascular system. The plant size varies in relation to the areas in which it grows, ranging from 15 to $100 \mathrm{~cm}$. Chemical composition of LC fibres are $82.4 \%$ holocellulose, $63 \% \alpha$-cellulose, $19.4 \%$ hemicellulose, 11.2 $\%$ lignin, $3.2 \%$ extractives, $0.4 \%$ ashes. Because of their composing cellulose, hemicellulose and lignin mainly, it is called as lignocellulose material [1-2].

Luffa products are natural, non-toxic, biodegradable and renewable resources. Their biodegrability can contribute to a healthier ecosystem, their low cost and good performance cause the interest of various industries, such as insulating, packaging and filling materials, composite applications and textile [2-4]. The researches on how to modify and use LC fibres as an alternative adsorbent are also available [4-8]. For the modification of the fibres different concentration of sodium hydroxide are used $[6,8]$. The effect of alkali treatment shown that the structure of the fibres is altered, its morphology and absorbency are changed [5-6].

For the treatment of textile effluents, many fungi and bacteria are used for the development of biological processes. Also there are a few studies about the textile dye decolourising ability. Ultrasonic energy has always been an alternative to the conventional methods. In textile processes, using ultrasonic energy has become popular because of positive results in bleaching and dyeing of textile materials. Cavitation is the formation and violent collapse of small bubbles or voids in the liquid as a result of pressure changes and causes longitudinal waves propagate through the liquid. This occurs different mechanical and chemical effects, such as degassing, intense agitation of the liquid, formation of free ions or radicals and dispersing [1-3].

The aim of this work was to dye untreated $100 \%$ LC fibres after carrying out various scouring and bleaching processes using conventional method and ultrasonic energy. The colour yield was compared with the dyeings that were carried out conventionally. According to the results of the methods applied, ultrasonic energy provided positive results in LC fibres in terms of hydrophilic characteristics and dye uptake.

\section{EXPERIMENTAL}

\subsection{Material}

Luffa cylindrica fibres were obtained from the Mediterranean Region of Turkey. Their overall lengths were between 400$600 \mathrm{~mm}$.

Corresponding Author: Burcu Y. ŞAHINBAŞKAN, Tel: +90 21641405 45, E-mail: byilmaz@marmara.edu.tr Submitted: 15 October 2014, Revised: 04 March 2015, Accepted: 01 July 2015 


\subsection{Equipment Used for the Treatments and Tests}

The equipment used for the dyeing by ultrasonic energy was Alex Ultrasonic Bath (220 volt and 205 Watt) with $32 \mathrm{kHz}+/-5$ frequencies. For the fastness tests, Gyrowash and Crockmeter were used. The reflectance values of the fibre samples were measured by Datacolor Spectraflash SF $600+$ instrument with specular included mode. The colour values of the fibres were calculated with D65 illuminant $/ 10^{\circ}$ observer values. Each fibre was measured in three different areas, twice on each side of the fibre for consistency, and the average value was calculated. The CIELab 1976 Colour Differences Formula was used to express the colour differences. UV-Vis spectroscopy (Shimadzu) was used for determines the dye amounts, which is not absorbed by the fibres during the dyeing processes at the wavelength of maximum absorbance ( $\max$ ) of the dye.

\subsection{Methods}

The LC fibres were pre-treated and dyed using conventional and ultrasonic assisted processes. Conventional Process: The samples $(5 \mathrm{~g})$ were scoured $1 \mathrm{~mL} / \mathrm{L}$ wetting agent (Uniwett HGA, Alfa Chemistry) and $10 \mathrm{~g} / \mathrm{L}$ sodium hydroxide (Merck) at $95^{\circ} \mathrm{C}$ for $60 \mathrm{~min}$ with a liquor ratio of $20: 1$. The scoured fibres were rinsed three times, for 10 minutes at each stage with a sequence of rinsing at $95{ }^{\circ} \mathrm{C}$, a second warm rinse at $60{ }^{\circ} \mathrm{C}$ and the last rinse at $30^{\circ} \mathrm{C}$. The samples were dryed at room temperature. The scoured fibres were bleached with 1 $\mathrm{mL} / \mathrm{L}$ wetting agent (Uniwett HGA, Alfa Chemistry), $1 \mathrm{~g} / \mathrm{L}$ sodium hydroxide, $2 \mathrm{~g} / \mathrm{L}$ organic stabiliser (Prestogen $\mathrm{D}$ BASF), $11 \mathrm{~mL} / \mathrm{L}$ hydrogen peroxide (35\%) (Merck) at $80^{\circ} \mathrm{C}$ for 45 minutes. After the conventional bleaching process, the fibers were washed at $70{ }^{\circ} \mathrm{C}$ for 20 minutes and neutralized, treated with $1 \mathrm{~g} / \mathrm{L}$ washing agent at $95^{\circ} \mathrm{C}$ for 10 minutes, and this was followed by two rinses at $70{ }^{\circ} \mathrm{C}$ for 20 minutes, finally a cold rinse was given 10 minutes and samples were dryed at room temperature. The dyeing process were carried out conventionally in separate baths and dyed by C.I. Reactive Red 241 (monochlortriazine) and C.I. Reactive Blue 19 (anthraquinone). The wavelengths of maximum absorbance ( $\max$ ) were 535 and $612 \mathrm{~nm}$, respectively. The dye bath contained $2 \%$ o.w.f. dye, $80 \mathrm{~g} / \mathrm{L}$ sodium sulphate (Merck) and $5 \mathrm{~g} / \mathrm{L}$ sodium carbonate (Merck) at liquor ratio of 20:1. The atmospheric dyeing was started at $60^{\circ} \mathrm{C}$ and left for $1 \mathrm{~h}$ at that temperature. Eventually the bath was then cooled and dyed fibres rinsed six times, for 10 minutes at each stage with a sequence of a warm rinsing at $70{ }^{\circ} \mathrm{C}$, a second warm rinse at $70{ }^{\circ} \mathrm{C}$ and neutralizing with acetic acid, soaping at the boil, a third rinse at $70^{\circ} \mathrm{C}$, a final rinse at $50{ }^{\circ} \mathrm{C}$ and eventually, a cold rinse. Ultrasonic Assisted Process: The fibres were scoured, bleached and dyed in separate baths described at conventional process with the help of ultrasonic power using ultrasonic bath.

\section{RESULTS}

The following results were obtained from the experimental work carried out on conventional methods and using ultrasonic energy. The small LC samples were taken out in the repeated experiments during the pre-treatment processes and the yellowness indexes of the samples were measured in accordance with ASTM D 1925-70 Method. As shown at Figure 1, the untreated (raw) samples yellowness index was $59 \pm 0.5$. The average yellowness values reached were, for conventional process, after alkali scouring $65 \pm 2.2$, after bleaching $41 \pm 0.6$, for ultrasonic assisted process, after alkali scouring $63 \pm 1.3$, after bleaching $42 \pm 0.3$ yellowness index. Both yellowness degrees were sufficient for the goods to be dyed for especially dark colours. The absorbency of the samples was checked in the accordance with AATCC test method 79-2000. The wetting time to bleached samples was found to be less than $1 \mathrm{~s}$.

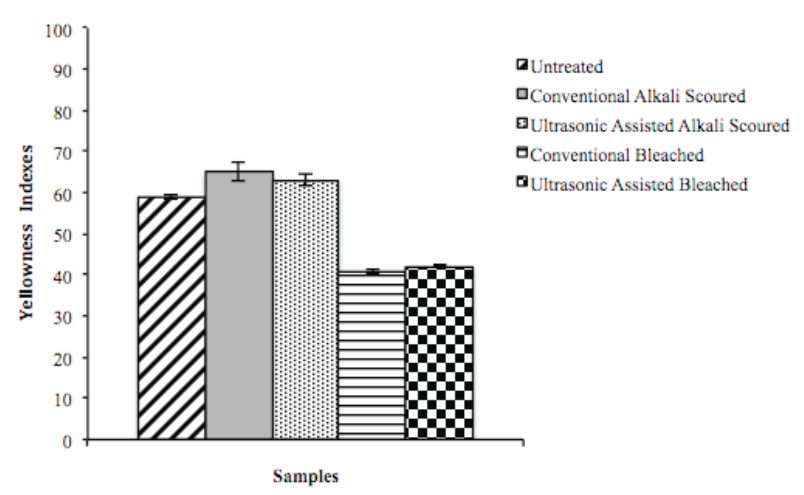

Figure 1. Yellowness indexes of the fibres.

\subsection{Colour Measurement Results of Dyed Samples}

The CIELab values, colour strength $(\mathrm{K} / \mathrm{S})$ values of the dyed samples and colour differences $\left(\Delta \mathrm{E}^{*}\right)$ are given in Table 1 . The $\mathrm{K} / \mathrm{S}$ values of the conventionally dyed samples are slightly higher than the ultrasonic assisted dyed samples. When the CIELab values of the dyed samples with ultrasonic energy are compared with conventional method, colour differences are present. These colour difference could be compensated because of not more than 3 CIELab $\Delta \mathrm{E}$ units for the most application. 


\subsection{Dye Uptake (\%)}

Bath samples taken every 20 minutes from the dye baths were diluted with distilled water and the dye amounts, which were not absorbed by the fibres during the dyeing processes at the wavelength of maximum absorbance $(\lambda \max )$ of the dye according to Beer- Lambert law using UV-Vis spectroscopy. The dye uptake was calculated by the method of least squares. The dye uptakes of dyed LC fibers with conventional and ultrasonic assisted processes can be seen at Figure $2 \mathrm{a}$ and $\mathrm{b}$. Using the ultrasonic power is increased the dye uptake for the anthraquinone reactive dye (95\%).

Table 1. The CIELab values of the dyed samples.

\begin{tabular}{|c|c|c|c|c|c|c|c|c|c|c|c|}
\hline \multirow[t]{2}{*}{ Dye } & \multirow[t]{2}{*}{ Process } & \multicolumn{5}{|c|}{ CIELab Values } & \multicolumn{3}{|c|}{ Tristimulus Values } & \multirow[t]{2}{*}{$\mathrm{K} / \mathrm{S}$} & \multirow{2}{*}{$\begin{array}{l}\text { Colour } \\
\text { Differences } \\
\left(\Delta \mathbf{E}^{*}\right)^{a}\end{array}$} \\
\hline & & $\mathbf{L}^{*}$ & $\mathbf{a}^{*}$ & $\mathbf{b}^{*}$ & $\mathbf{C}^{*}$ & $\mathbf{h}^{\circ}$ & $\mathbf{X}$ & $\mathbf{Y}$ & $\mathbf{Z}$ & & \\
\hline \multirow{2}{*}{$\begin{array}{l}\text { C.I. Reactive } \\
\text { Red } 241\end{array}$} & Conventional & 44.45 & 48.53 & -1.41 & 48.55 & 358.36 & 22.40 & 14.15 & 15.81 & 8.06 & \multirow[t]{2}{*}{2.25} \\
\hline & Ultrasonic Assisted & 43.94 & 46.43 & -2.04 & 46.48 & 357.48 & 21.49 & 13.80 & 15.71 & 16.73 & \\
\hline \multirow{2}{*}{$\begin{array}{l}\text { C.I. Reactive } \\
\text { Blue } 19\end{array}$} & Conventional & 28.43 & 0.11 & -29.44 & 29.44 & 270.22 & 5.34 & 5.62 & 16.00 & 7.93 & \multirow[t]{2}{*}{2.85} \\
\hline & Ultrasonic Assisted & 30.95 & -1.09 & -28.85 & 28.88 & 267.84 & 6.19 & 6.63 & 17.76 & 13.50 & \\
\hline
\end{tabular}

Table 2. Colour fastness properties of dyed fiber samples.

\begin{tabular}{|c|c|c|c|c|c|c|c|c|c|c|}
\hline \multirow[t]{2}{*}{ Dye } & \multirow[t]{2}{*}{ Process } & \multicolumn{7}{|c|}{ Washing Fastness $^{b}$} & \multicolumn{2}{|c|}{ Rubbing Fastness } \\
\hline & & $\mathrm{CC}$ & SCA & SC & SN & SP & SA & SW & Dry & Wet \\
\hline \multirow{2}{*}{$\begin{array}{l}\text { C.I. Reactive Red } \\
241\end{array}$} & Conventional & 5 & 5 & $4-5$ & $4-5$ & 5 & $4-5$ & $4-5$ & 5 & $4-5$ \\
\hline & Ultrasonic Assisted & 5 & 5 & $4-5$ & $4-5$ & 5 & $4-5$ & $4-5$ & 5 & 4 \\
\hline \multirow{2}{*}{$\begin{array}{l}\text { C.I. Reactive Blue } \\
19\end{array}$} & Conventional & 5 & 5 & 5 & $4-5$ & 5 & 5 & 5 & 5 & 4 \\
\hline & Ultrasonic Assisted & 5 & 5 & 5 & $4-5$ & 5 & 5 & 5 & 5 & 4 \\
\hline
\end{tabular}

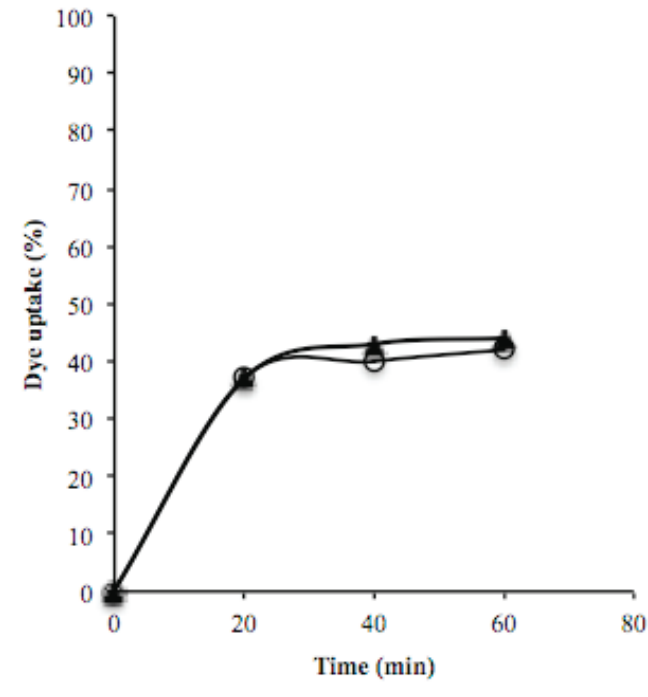

Figure 2.a. Dye uptake of dyed samples with C.I. Reactive Red 241

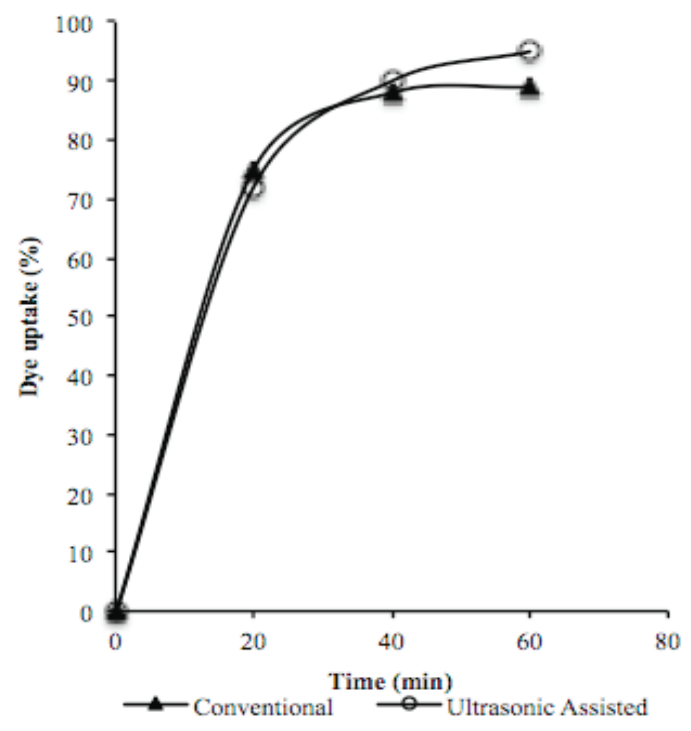

Figure 2.b. Dye uptake of dyed samples with C.I. Reactive Blue 19 


\subsection{Colour Fastness Test Results of Dyed Samples}

The washing and rubbing fastness test results are summarized in Table 2. The washing fastness tests are carried out in accordance with the method described in ISO 105-C06, A1S test conditions; $40{ }^{\circ} \mathrm{C}$ temperature, $30 \mathrm{~min}$ and 10 steel balls. The rubbing fastness tests are carried out in accordance with ISO 105 X12.

The washing fastness (4-5+), dry rubbing fastness (5) and wet rubbing fastness $(4+)$ test results are quite good.

\section{CONCLUSION}

This study has showed that;

- Yellowness indexes of LC fibre samples treated with conventional and ultrasonic assisted processes were quite good to be dyed for dark colours.

- The wetting time to conventional and ultrasonic assisted bleached samples was $<1$ s.

- LC fibre can be dyed with reactive dyes by conventional and ultrasonic assisted dyeing processes.

- The washing and rubbing fastness test results of the dyed samples were quite good.

- The use of ultrasonic energy was improved the dyeing yield of LC fibre with C.I. Reactive Blue 19.

\section{REFERENCES}

[1] Koçak,D., Merdan N., Yüksek, M., Sancak, E., Effect of Chemical Modifications on Mechanical Properties of Luffa cylindrica, Asian Journal of Chemistry, vol.25
(2), 2013, pp. 637-641.

[2] Koçak,D., The Study of The Effects of Different Chemical Compounds Applied on Luffa cylindrica Fibres with The Help of Ultrasonic Energy, Journal of Polymer Engineering, vol. 28(8), 2008, pp.501-515.

[3] Koçak, D., The Influence of Ultrasonic Energy on Chemical Treatment of Surface Properties and Properties of Composites Made of Luffa cylindrica Fiber-Polyester Resin, Journal of Engineering Materials and Technology, vol. 130(4), 2008, doi: 10.111511.2969251.

[4] Demir, H., Top, A., Balköse, D., Ülkü, S., Dye Absorption Behavior of Luffa cylindrica Fibers, Journal of Hazardous Materials, vol.153, 2008, pp.389-394.

[5] Bal, K.E., Bal, Y., Lallam, A., Gross Morphology and Absorption Capacity of Cell-Fibers From Fibrous Vascular System of Loofah (Luffa cylindrica), Textile Research Journal, vol. 74, 2004, pp.241-247.

[6] Ghali, L., Msahli, S., Zidi, M., Sakli, F., Effect of Pretreatment of Luffa Fibres on The Structural Properties, Materials Letters, vol.63, 2009, pp.61-63.

[7] Ruiz-Main, A., Campos-Garcia, S., Zavalo-Loria, J., Solana, F., Canedo-Lopez, Y., Assessment of Luffa cylindrica as Support in Biofilms Reactors for The Biological Treatment of Domestic Waste Water, Water Air Soil Pollut, vol.119, 2009, pp.13-21.

[8] Altınışık, A., Gür, E., Seki, Y., A Natural Sorbent, Luffa cylindrica For The Removal of A Model Basic Dye, Journal of Hazardous Materials, vol.179, 2010, pp.658-664. 